\title{
Assessment of mosquito collection methods for dengue surveillance
}

\section{Triwibowo Ambar Garjito}

IVRCRD

\section{Lulus Susanti}

IVRCRD

\section{Mujiyono Mujiyono \\ IVRCRD}
Mega Tyas Prihatin
IVRCRD

Dwi Susilo

IVRCRD

\section{Sidiq Setyo Nugroho}

IVRCRD

\section{Mujiyanto Mujiyanto}

IVRCRD

\section{Raden Ajeng Wigati}

IVRCRD

\section{Tri Baskoro Tunggul Satoto}

Gadjah Mada University: Universitas Gadjah Mada

\section{Sylvie Manguin}

IRD: Institut de recherche pour le developpement

\section{Laurent Gavotte}

University of Montpellier: Universite de Montpellier

\section{Roger Frutos ( $\nabla$ roger.frutos@cirad.fr)}

CIRAD https://orcid.org/0000-0002-8926-3119

\section{Research}

Keywords: Aedes aegypti, Aedes albopictus, dengue, collection methods, dengue incidence, Indonesia Posted Date: February 17th, 2021

DOl: https://doi.org/10.21203/rs.3.rs-100194/v3 
License: (c) (i) This work is licensed under a Creative Commons Attribution 4.0 International License. Read Full License

Version of Record: A version of this preprint was published at Frontiers in Medicine on June 8th, 2021. See the published version at https://doi.org/10.3389/fmed.2021.685926. 


\section{Abstract \\ Background}

Several methods exist to collect and assess the abundance of dengue vector mosquitoes, i.e. morning adult collection using an aspirator, pupal collection, various ovitraps, whole night collection using human landing methods, and larval collection. Several of these methods are officially implemented to monitor mosquito density and make decisions on treatments for dengue control. This monitoring is also constrained by the need to conduct this assessment on a "one point/one day" process. This diversity of methods might be a source of variability and lack of statistical significance. There is also a lack of published data regarding the effectiveness of these methods

\section{Methods}

A mosquito survey was conducted in 39 locations corresponding to 15 dengue endemic provinces in Indonesia. The larval surveys were performed by collecting at least one single Aedes larva from each container, and then reared up until hatching. Three adult mosquito sampling methods were also used, including morning resting collection, human landing collection, animal baited trap. All field samples were tested for dengue. Factor Analysis of Mixed Data (FAMD) was conducted to analyze the effectiveness of the collection methods against mosquito species and dengue incidence.

\section{Results}

A total of 44,675 mosquitoes were collected. The single larva method was the most efficient method. Out of a total of 89 dengue-positive pools, the most frequently encountered virus was DENV2, which made up half of the positive samples, followed by DENV3 and DENV1, respectively. FAMD showed that no correlation could be found between any methods and the presence of dengue virus in mosquitoes. Moreover, no correlation could be found between any methods and with the incidence.

\section{Conclusions}

There was no consistency in the efficacy of a given method and the incidence of dengue in the human population. There was no correlation between any of the parameters considered, i.e. method, incidence of dengue, location and presence of dengue virus in mosquitoes.

\section{Background}

Dengue is the most rapidly spreading arboviral disease worldwide [1]. Recent studies estimate that 55 to 100 million dengue cases are reported annually with 3.9 billion people at risk [2, 3]. Indonesia is an hyperendemic dengue country, i.e. all four serotypes are circulating, with the highest number of dengue 
cases in South-East Asia [4,5]. Dengue incidence in Indonesia has increased significantly over the last four decades from $0.05 / 100,000$ in 1968 to $78.8 / 100,000$ in 2016 [6]. The Dengue virus is transmitted to humans by the bite of infected Aedes aegypti mosquitoes, the main vector, and Ae. albopictus, the secondary vector. These species are anthropophilic, i.e. they live in human environments and breed in various sites, such as water containers, flowerpots, birdbaths, disposed water-holding vessels, waste disposal areas, small containers, discarded tires, natural holes in vegetation, etc. [7-10]. Both are present in urban and sub-urban areas. With no treatment and while an effective vaccine is still under study, vector control remains the only effective way to prevent and control dengue.

Vector surveillance methods have remained mostly unchanged for more than three decades [11]. Larval survey is the most widely adopted dengue vector surveillance method to locate larval habitats and to measure the abundance of Ae. aegypti and Ae. albopictus [12, 13]. The Stegomyia indices, i.e. House index $(\mathrm{HI})$, Container Index $(\mathrm{Cl})$ and Breteau index $(\mathrm{BI})$ to which a specific Free Larval Index (FLI) is added in Indonesia, are used for calculating mosquito abundance and for predicting the risk of dengue transmission [11]. However, previous studies have demonstrated the lack of correlation between Stegomyia indices and the risk of dengue outbreak [12,14-18], while a correlation was found between human population density and incidence of dengue [18]. This sounds logical owing to the anthropophilic behavior of these vectoring mosquitoes. Several methods for collecting mosquitoes are officially recommended by the Ministry of Health, i.e. morning adult collection using an aspirator, pupal collection, various ovitraps, whole night collection using human landing methods, and larval collection. Since the Stegomyia indices, exclusively based on larval collection, are not reliable predictors, other predicting parameters must be sought. The diversity of methods endorsed by the Ministry might be a source of variability. Furthermore, there is a lack of published data regarding the effectiveness of these methods $[12,19-22]$. A major constraint associated with the monitoring of mosquitoes is that the decision for treatment or absence of treatment is made on a one day/one place basis. Therefore, we conducted a comparative analysis to assess their relative effectiveness in the framework of a routine surveillance process.

\section{Methods}

Study Sites. The study was conducted in 39 locations corresponding to 39 districts/municipalities in 15 dengue endemics provinces in Indonesia (Fig. 1). These provinces include Aceh, West Sumatra, Lampung, Bangka-Belitung, West Kalimantan, South Kalimantan, North Sulawesi, East Java, South-East Sulawesi, Maluku, West Nusa Tenggara, North Maluku. This study is part of the Indonesia national project, Rikhus Vektora led by the Ministry of Health that started in 2016

Study design. A mosquito survey was performed in all study sites from July to August 2016, during the rainy season. Single larval methods were performed randomly in at least 100 households in each study site during the study. Aedes larvae were collected and then reared in a field laboratory by using plastic trays with tap water and fish food for 3-4 days. Adult collection of Aedes mosquitoes were performed in the morning (morning resting) on mosquitoes resting inside houses using manual aspirators. Adult 
mosquitoes were also collected outside using standard procedures for all night human-landing collection methods from $6.00 \mathrm{pm}$ to $6.00 \mathrm{am}$. Each adult collection method was performed in every study site. All methodologies used in this study are described in the Ministry of Health guidelines [22]. All methodologies investigated must be compatible with the "one day/one place" process of decision making. Field data collections for larva and adult Aedes mosquitoes were performed by trained collectors in collaboration with local volunteers, local authorities and staff from district/municipality dengue control programs.

\section{Single larva and rearing methods}

The larval surveys were performed by collecting at least a single Aedes larva from each container. All larvae then were taken to the field laboratory located in the study sites and reared up to the fourth days until adult hatching. Emerged adult mosquitoes were then killed in a freezer $\left(-20^{\circ} \mathrm{C}\right)$ or by using ethyl acetate for 5 to 10 minutes and immediately stored in $1.5 \mathrm{ml}$ vial tubes with RNAlater (Qiagen, Hilden, Germany) by pools of 25 mosquitoes and kept refrigerated at $4^{\circ} \mathrm{C}$ prior to further analysis. Reared larvae and pupae that did not hatch to adult stage up to the fourth days were preserved under the same conditions for further analysis.

\section{Adult mosquito collection methods}

Three adult mosquito sampling methods were conducted simultaneously in all study sites, including: (1) morning resting collection, (2) human landing collection, (3) animal baited trap.

(1). Morning resting collections were made by eight collectors using hand nets and aspirators. Collections were conducted from 7.00 am to 9.00 am and included any resting locations within the house. All adult mosquitoes were placed into labelled paper caps and taken to the field laboratory for further analysis.

(2). Human landing collection were performed by eight local volunteers as collectors in three selected houses of each study sites for sampling adult mosquitoes using mouth aspirators. They were all trained before collecting mosquitoes. Three teams of two people sampled outdoors (up to 5 meters from the house) and indoors (inside the house). Each collector sat on chairs with exposing their legs for 50 of 60 minutes per hour. Sampling was conducted all night from $6.00 \mathrm{pm}$ to $6.00 \mathrm{am}$. The teams rotated and changed roles regularly every 2 hours with a 2 hour-break. Although, the targeted Aedes mosquitoes are diurnal, the Indonesia law does not allow human landing collections during day time. Therefore, collections had to be conducted at night. This introduces a strong bias in the sampling but since it is what surveillance teams do in accordance with the law, this method was nevertheless performed. Mosquitoes that have been collected per hour were then taken to the field laboratory for species identification and further analysis.

(3). Animal baited trap was conducted by using tame animal, i.e. cows, placed inside a net all night. Mosquito collections were carried out for 15 minutes per hour inside the nets by 3 collectors. Collected mosquitoes were then similarly preserved as for the human landing collection method. 
All mosquitoes from these three collecting methods identified as Ae. aegypti and Ae. albopictus were then killed with ethyl acetate, pooled up to 25 mosquitoes in labelled $1.5 \mathrm{ml}$ vial tubes with RNAlater (Qiagen, Hilden, Germany) and preserved based on the same cold chain management as above for larvae.

Detection of Dengue virus from mosquitoes. The Ae. aegypti and Ae. albopictus mosquito pools were homogenized in $1.5 \mathrm{ml}$ tubes containing $200 \mu$ PBS $1 \mathrm{x}$ by using pellet pestles. RNA was extracted using QIAamp ${ }^{\circledR}$ Viral RNA Mini Kit (Qiagen ${ }^{\circledR}$, Courtaboeuf, France). RNAs were extracted from 200- $\mu$ l homogenized samples following the manufacturer's instructions. All RNA extracted samples were analyzed for Dengue detection using Lanciotti's protocol [23]. The nested RT-PCR for Dengue was performed using SimpliAmp Thermal Cycler Applied Biosystems ${ }^{\mathrm{TM}}$ (ThermoFisher Scientific ${ }^{\circledR}$, United States). Amplification of Dengue RNA was carried out with following specific primers: D1 (5'-TCA ATA TGC TGA AAC GCG CGA GAA ACC G-3'), D2 (5'-TTG CAC CAA CAG TCA ATG TCT TCA GGT TC-3'), TS1 (5'CGT CTC AGT GAT CCG GGG G-3'), TS2 (5'-CGC CAC AAG GGC CAT GAA CAG-3'), TS3 (5'-TAA CAT CAT CAT GAG ACA GAG C- $3^{\prime}$ ), and TS4 (5'-CTC TGT TGT CTT AAA CAA GAG A-3'). The first amplification of Dengue virus was performed using Superscript III one-step RT-PCR kit (Invitrogen, Carlsbad, CA). The cycling conditions consisted of initial $95^{\circ} \mathrm{C}$ denaturation step for 2 minutes, followed by 40 cycles of $95^{\circ} \mathrm{C}$ denaturation for 30 seconds, $60^{\circ} \mathrm{C}$ annealing for 1 minute, and $72^{\circ} \mathrm{C}$ extension for 1 minute 30 seconds, and a final extension step $72^{\circ} \mathrm{C}$ for 10 minutes. Samples were then stored at $4^{\circ} \mathrm{C}$. First step PCR products were run on $2 \%$ agarose gel under $120 \mathrm{~V}$ current for 1 hour and followed by visualization using SYBR ${ }^{8}$ safe DNA gel stain (Invitrogen, Carlsbad, CA, USA) under UV condition in GelDoc system and check for presence of the $511 \mathrm{bp}$ control band corresponding to dengue virus (DENV) positive. Subsequent serotyping was conducted by using 1 st step PCR product with thermal cycle setting as follow: initial denaturation step at $95^{\circ} \mathrm{C}$ for 2 minutes, followed by 10 cycles of denaturation step at $95^{\circ} \mathrm{C}$ for 30 seconds, $60^{\circ} \mathrm{C}$ annealing for 1 minute, and an extension step at $72^{\circ} \mathrm{C}$ for 1 minute and 30 seconds. The final extension step was conducted at $72^{\circ} \mathrm{C}$ for 10 minutes. Subsequently, samples were stored at $4^{\circ} \mathrm{C}$. Amplification product on $2 \%$ agarose gel were then carried out under $80 \mathrm{~V}$ current for 1 hour and check under UV condition. Multiplex serotyping reaction is expected to produce single-specific band with the size of 482bp for DENV-1, 119bp for DENV-2, 290bp for DENV-3, and 389bp for DENV-4. All of field samples were tested for the presence of dengue virus after being pooled by 25 individuals of the same species.

\section{Statistical analyses}

A first Factor Analysis of Mixed Data (FAMD) [24] was conducted using the incidence data, the number of mosquitoes and the number of positive pools for each dengue serotype as quantitative parameters, and mosquito species, methods of collection and provinces as qualitative parameters. The effectiveness of the collection methods (qualitative data) against mosquito species (quantitative data) was assessed using a second FAMD. These analyses were performed using the R software with FactoMineR [25].

\section{Results}


Mosquito sampling. A total of 44,675 mosquitoes were collected from 39 locations (Fig. 1, Supplementary Table 1). Out of these 44,675 mosquitoes collected, 32,525 (72.8\%) were Ae. aegypti and 10,300 (23.1\%) were Ae. albopictus, while 1,850 (4.1\%) were undetermined. When considering the method of capture, the highest number of captured individuals was, as expected, obtained when targeting larvae. The single larva method was the most efficient in terms of number of individuals collected. A total of 36,500 larvae were collected with this method out which 27,475 were Ae. aegypti, 7,775 were Ae. albopictus and 1,250 were not identified. The rearing method, although less efficient also yielded large numbers of individuals. Out of 6,450 larvae collected and reared, 4,325 were Ae. aegypti, 1,575 were Ae. albopictus and 550 were not identified. With both larval methods a bias was observed in favor of $A e$. aegypti which represented $75.27 \%$ and $37.05 \%$ of all samples for the single lava and rearing methods, respectively. Very different results were obtained with the adult capture method. From the three methods used, human landing was the most efficient even though a bias is introduced by the legal obligation to perform this approach by night. Out of 1,325 adult mosquitoes captured 325 were Ae. aegypti, 975 were Ae. albopictus and 25 were not identified. The higher proportion of Ae. albopictus might be related to the fact this species is more crepuscular than Ae. aegypti. The animal baited trap method yielded only 25 mosquitoes, all being Ae. albopictus. The ratio between Ae. aegypti and Ae. albopictus was reversed with a bias this time in favor of Ae. albopictus. It represented $73.58 \%$ and $53.33 \%$ for the human landing and morning resting methods, respectively. The animal baited trap method yielded only Ae. albopictus, but considering the very low number of mosquitoes captured, i.e. 25 , this is not significant.

Distribution of dengue virus. A total of 89 pools were positive for dengue virus. The most frequently encountered virus was DENV2 $(n=44)$, which made up half of the positive samples. DENV3 and DENV1 followed with 20 and 17 positive pools, respectively. DENV4 was detected in only one pool. Combinations were also detected. 8 pools contained a combination of DENV1 and DENV2, whereas the combination of DENV1 and DENV3 was found in only one pool. Another single pool contained the triple combination DENV1-DENV2-DENV3. With respect to the geographic distribution, a strong imbalance was observed. A large part of the detected dengue viruses, i.e. 56 (63\%), were found in mosquitoes collected in the province of Aceh. All four dengue virus serotypes and all positive combinations were found in this province. The other provinces where positive pools were detected are: West Sumatra $(n=5)$, Lampung ( $n$ $=6)$, Bangka-Belitung $(n=4)$, West Kalimantan $(n=2)$, South Kalimantan $(n=1)$, North Sulawesi $(n=2)$, East Java $(n=7)$ and Maluku $(n=6)$. A strong imbalance was also observed when considering the nature of the positive samples. Mosquito larvae were the almost exclusive source of virus, i.e. $93.3 \%(n=83)$, with $70.8 \%(n=63)$ found with the single larva method and $22.5 \%(n=20)$ for the rearing method. Only 6 pools $(6.7 \%)$ of adult mosquitoes were found positive with the human landing method totalizing 2 pools $(2.3 \%)$, while 4 pools $(4.4 \%)$ were found positive in mosquitoes collected with the morning resting method. An imbalanced result was also found regarding the mosquito species with $76.4 \%(n=68)$ of the positive pools corresponding to Ae. aegypti and 23.6\% $(n=21)$ corresponding to Ae. albopictus.

Correlation assessment. A Factor Analysis of Mixed Data (FAMD) was performed to determine the potential correlation between the various parameters considered: mosquito species, province, number of mosquitoes, collection method, dengue virus and dengue incidence (Fig. 2a). The only correlation which 
could be found was between the province and the incidence (Fig. 2a). However, the global level of explanation was low $(20 \%)$ indicating a lack of correlation between any of the parameters with the exception of province and incidence of dengue. A similar result was found when comparing the different collection methods with the mosquito species. The only, but rather weak, correlation which could be found was the preferred association of the larval methods with Ae. aegypti and the adult methods with Ae. albopictus (Fig. 2b, Supplementary Table 1).

\section{Discussion}

In the absence of commercialized vaccines and of any medical treatment, the management of dengue relies only on mosquito control and on prevention. Finding efficient and reliable descriptors for assessing the risk of dengue outbreaks is thus a priority in all dengue-endemic countries. The main tools currently in use for assessing this risk of dengue outbreak is the Stegomyia indices $[15,26]$ which rely on the calculation of the relative density of mosquito larvae present in containers and in households through the Container Index $(\mathrm{Cl})$, the House Index $(\mathrm{HI})$ and the Breteau Index $(\mathrm{BI})[26,27]$. However, these indices were shown to display no correlation with dengue infection rates and are thus not reliable descriptors $[18,28-$ 30].

The development of descriptors, and in the first place entomological indices other than the Stegomyia indices, must then be envisioned. However, as entomological indices, they will still be based on the capture of mosquitoes regardless of the calculation model applied. They must also be compatible with the logistical and administrative constraint of the "one day/one place" nature of the operational monitoring and decision process. Agents conducting mosquito surveys do not spend all the time at the same place and make their calculations and assessments, and release their conclusions within one day. The window for deciding on treatment is also narrow since treatments must be effective before outbreaks occur. Long-term assessments within a single place are scientific experimentations for the purpose of understanding biological processes or developing techniques and methodology, and are not intended for decision making. This constraint is even more important in large countries like Indonesia. As a consequence, trapping methods, which are long-term methods based on cumulated data, are not favored.

We therefore conducted this large-scale study to assess the procedures endorsed by the Ministry of Health in guidelines within a very large study involving many sampling sites corresponding to different urbanistic and geographical conditions. The methods implemented must be reliable regardless of the location and local conditions. This work is to our knowledge the most extensive one with 44,675 mosquitoes collected in 39 different sampling locations over Indonesia within a short two-month period, allowing thus a robust statistical analysis. The main conclusion of this work is that it is not the Stegomyia indices only, but any kind of entomological indices that might be at best of very limited use. Not only no correlation could be found between any methods and the presence of dengue virus in mosquitoes but no correlation could be found between either any methods or the incidence. No consistency was found either for a given method from one place to another. Finally, there was no consistency in the efficiency of a given method for detecting dengue. The single-larva and rearing 
methods yielded $63 \%$ of all dengue-positive samples in the sole province of Aceh. However, the incidence of dengue in Aceh is not the highest among all provinces and is rather in the average. Provinces displaying the highest incidence such as Bangka-Belitung, South Kalimantan or North Sulawesi did not yield any dengue-positive larvae. The only single positive pool in these provinces was found in South Kalimantan among morning resting adults. This lack of correlation between incidence and dengue infection rate in mosquitoes is also a drawback for methods associating the capture of adults and the direct detection of dengue virus in the sampled mosquitoes [31-33].

The use of Stegomyia indices and the monitoring of mosquitoes are today the main means of assessing the risk of dengue outbreaks and efficiency of mosquito control. Previous studies have demonstrated the lack of correlation of the Stegomyia indices with the risk of dengue outbreaks and dengue incidence [12, 14-18]. In this work we demonstrated the lack of consistency of the various collection methods officially recommended and the lack of correlation with the recorded dengue incidence. Altogether, this indicates that entomological approaches other than the Stegomyia indices do not provide reliable indicators of risks of dengue outbreak either. The risk with these methods is mostly that of misleading interpretation, and misguided decisions and allocation of resources. The assessment of the risk of dengue outbreaks should be considered from a different angle.

\section{Conclusions}

A previous study found that a factor positively correlated with the incidence of dengue was the human population density [18]. This provides an angle for further researches. Ae. aegypti and Ae. albopictus are both anthropophilic species and the human environment is a thus a major driver of their demography and distribution. The measurement and prediction of the risk of dengue outbreaks should be considered from the angle of urbanism and human societal factors. Efforts should be devoted to the development of novel societal indices. It is even more important to communicate on this issue because dengue endemic countries worldwide, as well as WHO, still base their recommendations and dengue management procedures on entomological indices.

\section{Abbreviations}

HI: House Index, Cl: Container Index, Bl: Breteau Index, FAMD: Factor Analysis of Mixed Data

\section{Declarations}

\section{Acknowledgements}

Authors express their gratitude to all field mosquito collectors, the experts, technical team and validators of the Rikhus Vektora project for great support. The authors would also like to thank the head of Laboratory Data Management NIHRD, MoH Indonesia who have permitted to do further analyses. The authors also gratefully acknowledge especially Widiarti, Mochammad Choirul Hidajat, Dhian Prastowo, 
Riyani Setyaningsih, Yusnita Mirna Anggraeny, Siti Alfiah, Evi Sulistyorini, Lasmiati, Sapto Prihasto Siswoko, Warido, Valentinus Widiratno, Rima Tunjungsari Dyah Ayuningtyas, Fahmay Dwi Ayuningrum, Ary Octsari Yanti, Sekar Negari Kusumaningtyas, Jeri Cahyandaru, Indira Diah Utami, Happy Anita Putri, Syarifah Nurhayati, Senja Rahayu Kinanti, Wahyu Sri Kunto and other members of the IVRCRD-NIHRD, $\mathrm{MoH}$ Indonesia for all support of fieldwork and laboratory work.

\section{Ethics approval}

This study involved the use of humans to collect adult mosquitoes in natural settings. Formal approval to conduct these activities was provided by the Ethical Commission Board of the NIHRD, Ministry of Health, Indonesia (No. LB.02.01/5.2/KE.003/2016 and No. LB.02.01/5.2/KE.020/2017).

\section{Consent for publication}

Not applicable

\section{Availability of data and materials}

Data supporting the conclusions of this article are included within the article.

\section{Competing interest}

The authors declare that they have no competing interests.

\section{Funding}

The research was supported by the Institute for Vector and Reservoir Control Research and Development, National Institute of Health Research and Development, Ministry of Health Indonesia. SM, LG and RF were supported by the Université de Montpellier, IRD, ISEM, and CIRAD, Montpellier, France. The project was supported in part by the French-Indonesian Nusantara projects Zika \& Co and SOCIAL

\section{Authors Contributions}

TAG, LS, TBT, WI, MTP conceived and designed the field studies. MO, SSN, DS prepared samples. TAG and MTP ran molecular analyses and laboratory experiments. TAG, LG and RF analyzed the data. MA prepared the map. TAG and RF wrote the manuscript. SM, LG and RF provided critiques and significant revisions to the manuscript.

\section{References}

1. Organization WH. Global Strategy for Dengue Prevention and Control 2012-2020. World Heal Organiszation, Geneva, Switz. 2012;35.

2. Ritchie SA. Dengue Vector Bionomics: Why Aedes aegypti is Such a Good Vector. In: Duane J Gubler, Eng Eong Ooi, Subhash Vasudevan JF, editor. Dengue and Dengue Hemorrhagic Fever 2nd edition. 
Boston, USA: CAB International; 2014. p. 455-480.

3. Nadjib M, Setiawan E, Putri S, Nealon J, Beucher S, Hadinegoro R, et al. Economic burden of dengue in Indonesia. PLoS Negl Trop Dis. 2019;13:1-14.

4. Maula AW, Utarini A. Ten-years trend of dengue research in Indonesia and South-east Asian countries: a bibliometric analysis. Glob Health Action. Taylor \& Francis; 2018;11.1.

5. World Health Organization. Treatment, prevention and control global strategy for dengue prevention and control 2012-2020 [Internet]. 2012. 43 p. Available from: http://apps.who.int/iris/bitstream/10665/75303/I/9789241504034_eng.pdf

6. MoH-Indonesia. Situasi Demam Berdarah Dengue di Indonesia [Internet]. Pusat data dan Informasi Kementerian Kesehatan Rl; 2018. p. pp7. Available from: file:///C:/Users/asus/Downloads/InfoDatinSituasi-Demam-Berdarah-Dengue.pdf

7. Sutherst RW. Global Change and Human Vulnerability to Vector-Borne Diseases. Clin Microbiol Rev. 2004; 17:136-173.

8. Mulligan K, Elliott SJ, Schuster-Wallace C. The place of health and the health of place: Dengue fever and urban governance in Putrajaya, Malaysia. Health \& Place. 2012;18:613-620.

9. Mendonca HFMS de, Ferreira AL, Santos CB dos, Rezende HR, Ferreira GEM, Leite GR, et al. Breeding sites of Aedes aegypti in metropolitan vacant lots in Greater Vitória, State of Espírito Santo, Brazil. Rev Soc Bras Med Trop. 2011;44:243-246.

10. Hawley WA. The biology of Aedes albopictus. J Am Mosq Control Assoc Suppl. 1988;1:1-39.

11. Kusriastuti R, Sutomo S. Evolution of Dengue Prevention and Control Programme in Indonesia DF / DHF Disease Burden. Dengue Bull. 2005;29:1-7.

12. Resende MC De, Silva IM, Ellis BR, Eiras ÁE. A comparison of larval, ovitrap and MosquiTRAP surveillance for Aedes (Stegomyia) Mem Inst Oswaldo Cruz. 2013;108:1024-1030.

13. Nathan MB. Critical review of Aedes aegypti control programs in the Caribbean and selected neighboring countries. J Am Mosq Control Assoc. 1993;9:1-7.

14. Focks D. A Review of Entomological Sampling Methods and Indicators for dengue Vectors. Special Program for Research and Training in Tropical Diseases (TDR). UNICEF, UNDP, World Bank, WHO Spec Program Res Train Trop Dis. 2003;28:208389.

15. Bowman LR, Runge-Ranzinger S, McCall PJ. Assessing the Relationship between Vector Indices and Dengue Transmission: A Systematic Review of the Evidence. PLoS Negl Trop Dis. 2014;8:e2848.

16. Chang FS, Tseng YT, Hsu PS, Chen CD, Lian I Bin, Chao DY. Re-assess Vector Indices Threshold as an Early Warning Tool for Predicting Dengue Epidemic in a Dengue Non-endemic Country. PLoS Negl Trop Dis. 2015;9:1-20.

17. Cromwell EA, Stoddard ST, Barker CM, Van Rie A, Messer WB, Meshnick SR, et al. The relationship between entomological indicators of Aedes aegypti abundance and dengue virus infection. PLoS Negl Trop Dis. 2017;11:1-22. 
18. Garjito T A, Hidajat M C, Kinansi R, Setyaningsih R, Anggraeni Y M, Mujiyanto, Trapsilowati W, Jastal, Ristiyanto, Satoto T B T, Gavotte L, Manguin S, Frutos R Stegomyia indices and risk of dengue transmission: a lack of correlation Frontiers in Public Health. 2020;8:328.

19. Morrison AC, Astete H, Chapilliqun F, Ramirez-Prada G, Diaz G, Getis A, et al. Evaluation of a sampling methodology for rapid assessment of Aedes aegypti infestation levels in Iquitos, Peru. J Med Entomol. 2004;41:502-510.

20. Focks D, Chadee DD. Pupal survey at epidemioogically significant surveillance method for Aedes aegypti: an example using data from Trinidad. Am J Trop Med Hyg. 1997;56:159-167.

21. Malaria entomology and vector control: Tutor's guide. 2013. http://whqlibdoc.who.int/hq/2003/WHO_CDS_CPE_SMT_2.

22. Manual on Mosquitoes Field Sampling Methods (In Bahasa Indonesia). http://www.b2p2vrp.litbang.kemkes.go.id/publikasi/download/59.

23. Lanciotti R S, Calisher C H, Gubler D J, Chang G J, Vorndam A V. Rapid detection and typing of dengue viruses from clinical samples by using reverse transcriptase-polymerase chain reaction. $J$ Clin Microbiol. 1992;30:545-551.

24. Pagès J. Analyse Factorielle de Donnees Mixtes. Revue Statistique Appliquée 2004;4:93-111.

25. Lê S, Josse J, Husson F. FactoMineR: An R Package for Multivariate Analysis. Journal of Statistical Software. 2008;25:1-18.

26. World Health Organization. Dengue: guidelines for diagnosis, treatment, prevention and Control. 2009. Available from : https://www.who.int/rpc/guidelines/9789241547871/en/

27. Pan American Health Organization. Dengue and dengue hemorrhagic fever in the Americas: guidelines for prevention and control. Sci Publ no. 548 Washingt Organ. 1994.

28. Wijayanti SP, Sunaryo S, Suprihatin S, McFarlane M, Rainey SM, Dietrich I, Schnettler E, Biek R, Kohl A. Dengue in Java, Indonesia: relevance of mosquito indices as risk predictors. PLoS Negl Trop Dis. 2016;10:e0004500.

29. Agha SB, Tchouassi DP, Bastos AD, Sang R. Assessment of risk of dengue and yellow fever virus transmission in three major Kenyan cities based on Stegomyia PLoS Negl Trop Dis. 2017;11:e0005858.

30. Chang FS, Tseng YT, Hsu PS, Chen CD, Lian I Bin, Chao DY. Re-assess vector indices threshold as an early warning tool for predicting dengue epidemic in a dengue non-endemic country. PLoS Negl Trop Dis. 2015;9:1-20.

31. Muller DA, Frentiu FD, Rojas A, Moreira LA, O'Neill SL, Young PR. A portable approach for the surveillance of dengue virus-infected mosquitoes. Journal of virological methods. 2012;183:90-93.

32. Lau SM, Chua TH, Sulaiman WY, Joanne S, Lim YAL, Sekaran SD, Chinna K, Venugopalan B, Vythilingam I. (2017). A new paradigm for Aedes surveillance using gravid ovipositing sticky trap and NS1 antigen test kit. Parasites \& Vectors. 2017;10:151. 
33. Wasik D, Mulchandani A, Yates MV. Point-of-use nanobiosensor for detection of dengue virus NS1 antigen in adult Aedes aegypti: A potential tool for improved dengue surveillance. Analytical chemistry. 2018;90:679-684.

\section{Figures}

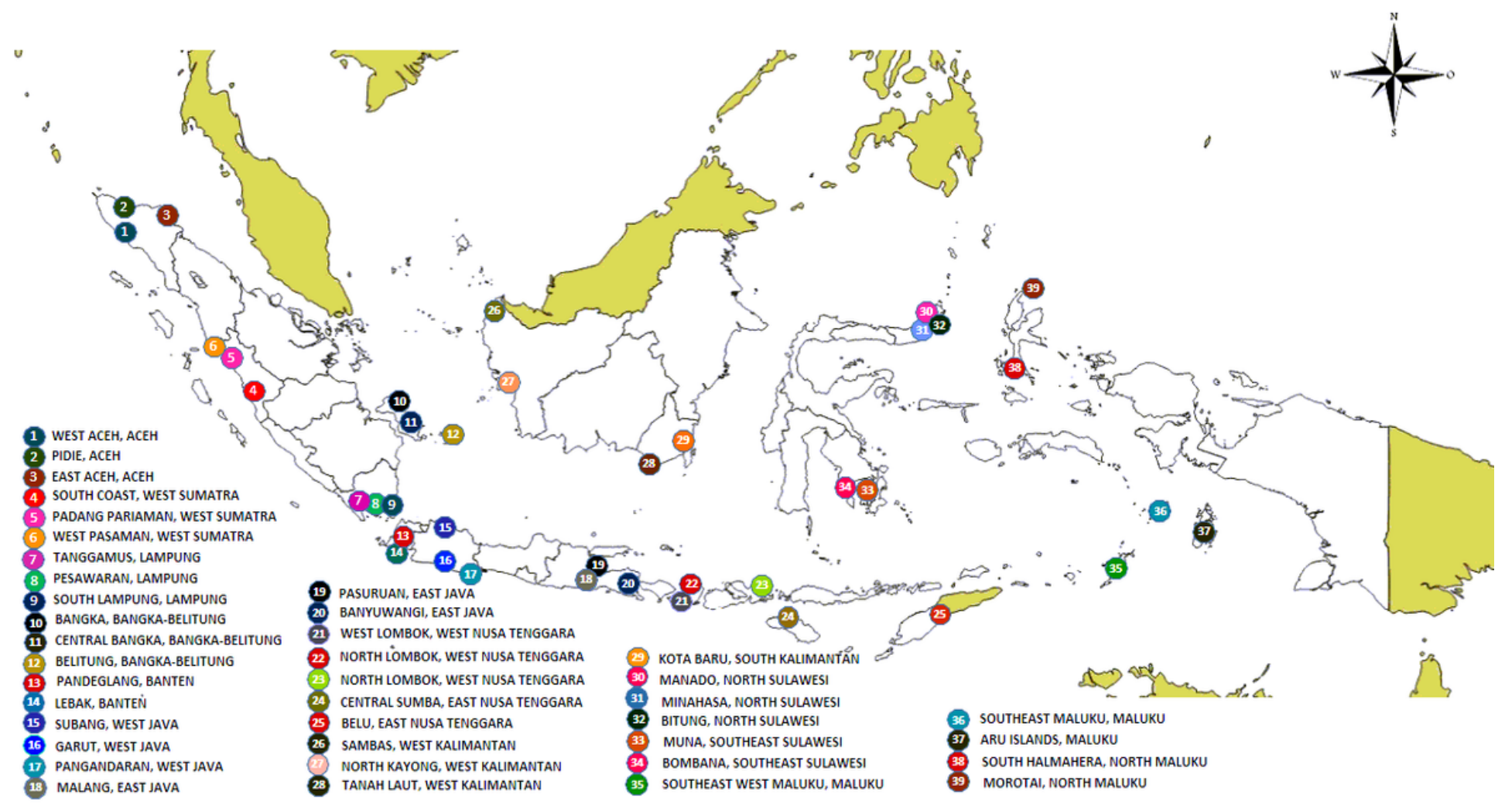

\section{Figure 1}

Map of the sampling sites throughout Indonesia. Note: The designations employed and the presentation of the material on this map do not imply the expression of any opinion whatsoever on the part of Research Square concerning the legal status of any country, territory, city or area o bbnhjr of its authorities, or concerning the delimitation of its frontiers or boundaries. This map has been provided by the authors. 

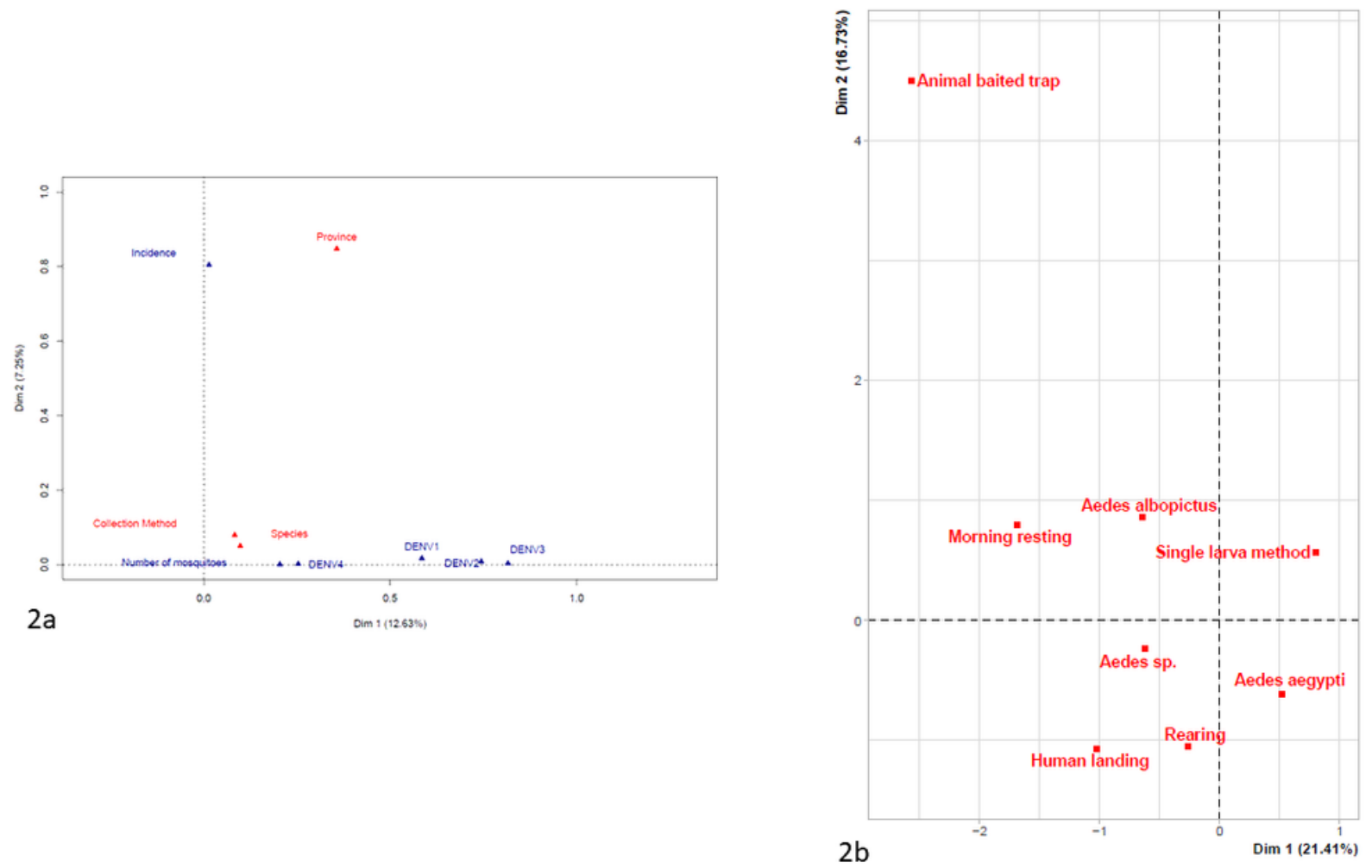

\section{Figure 2}

Multivariate analysis of parameters 2a. Global Factor Analysis of Mixed Data 2b. FAMD assessment of the effectiveness of the collection methods

\section{Supplementary Files}

This is a list of supplementary files associated with this preprint. Click to download.

- Graphicalabstract.tif

- SupplementaryTable1CollectionMethodsPV.xlsx 